\title{
Comparative study of synthetic and semi-synthetic lubricating oils and their lubricating capacities
}

\author{
Eudes da Silva Ramos ${ }^{1}$, Tadeu Ramos Pinto Junior ${ }^{2}$, Raimundo Nonato Alves da Silva ${ }^{3}$, Gizele Melo Uchoa ${ }^{4}$, \\ Vanise dos Santos Rodrigues ${ }^{5}$, Greyce dos Santos Rodrigues ${ }^{6}$
}

\author{
${ }^{1,2,3}$ Centro Universitário do Norte (UNINORTE). Manaus -Amazonas - Brasil. \\ 4,5 Instituto de Tecnologia e Educação Galileo da Amazônia (ITEGAM).Manaus-Amazonas. Brasil. \\ eudes_ramos@yahoo.com.br, tadeuramos353@live.com, raimundo.nonato.silva@gmail.com, vanise_santosrodrigues@hotmail.com, \\ greyce.gsr@gmail.com
}

Received: September $21^{\text {th }}, 2016$

Accepted: November $13^{\text {th }}, 2016$

Published: December, $22^{\text {th }}, 2016$

Copyright (C2016 by authors and Institute of Technology Galileo of Amazon (ITEGAM) This work is licensed under the Creative Commons Attribution International License (CC BY 4.0).

http://creativecommons.org/licenses/by/4.0/ cc) (i)(2)(2) Open Acests

\section{ABSTRACT}

With the growth of the fleet of vehicles in recent years, it becomes essential to know the quality of the most used automotive lubricating oils on the market. The aim of this research was to analyze the performance of synthetic and semi-synthetic lubricants of Shell brand, synthetic lubricating oil used was 5W-40 and semi-synthetic was $10 \mathrm{~W}-40$, both had the same SAE viscosity of 40, On the packaging. Through experimental observations and laboratory tests used on the engine of a Gol City type 1.62014 Flex-type car that traveled 5,000 km with each lubricating oil. The research in question is relevant since many consumers of automotive vehicles do not have the specific knowledge about the quality of the lubricants taking into account only the price of the lubricating oil used. The research provided the knowledge of the physical properties through the kinematic viscosity test and viscosity index that were performed in a "Saybolt" viscometer, the results obtained in this step were converted to "centistokes" according to the approximate system conversion multiplication factors Of viscosity. The observation tests, water contamination in which a heating plate was used, were also carried out to verify which of the lubricating oils present the highest contamination by water.

Keywords: Viscosity, Engine, Lubricating Oil, Synthetic, Semi-Synthetic.

Estudo comparativo de óleos lubrificantes sintéticos e semissintético e suas capacidades de lubrificação

\begin{abstract}
RESUMO
Com crescimento da frota de veículos nos últimos anos, torna-se primordial o conhecimento da qualidade dos óleos lubrificantes automotivos mais utilizados no mercado. Essa pesquisa tem como objetivo analisar o desempenho dos óleos lubrificantes de bases sintéticas e semissintéticas da marca Shell, óleo lubrificante sintético utilizado foi o $5 \mathrm{~W}-40$ e o semissintético foi o 10W-40, os dois apresentam o mesmo grau de viscosidade SAE de 40, apresentado na embalagem. Através de observações experimentais e ensaios em laboratório utilizados no motor de um automóvel tipo Gol City 1.62014 do tipo Flex que percorreu $5.000 \mathrm{~km}$ com cada óleo lubrificante. A pesquisa em questão é relevante tendo em vista que grande parte dos consumidores portadores de veículos automotivos não detém o conhecimento especifico sobre a qualidade dos lubrificantes levando em consideração somente o preço do óleo lubrificante utilizado. A pesquisa proporcionou o conhecimento das propriedades físicas através do teste de viscosidade cinemática e índice de viscosidade que foram realizados em um viscosímetro "Saybolt", os resultados obtidos nessa etapa foram convertido para "centistokes", segundo os fatores de multiplicação de conversão aproximada de sistema de viscosidade. Também foram realizados os testes de observação, contaminação por água em que foi utilizado uma chapa aquecedora, para verificar qual dos óleos lubrificante apresentam maior contaminação por água.
\end{abstract}

Palavras Chaves: Viscosidade, Motor, Óleo Lubrificante, Sintético, Semissintético. 


\section{INTRODUÇÃO}

Os lubrificantes automotivos sintéticos e semissintéticos deveram ganhar espaço no mercado mundial à medida que os veículos com maior exigência de desempenho aumentam a sua demanda. As companhias mundiais de óleo Lubrificantes estão focando na venda de produtos com maior valor agregado que são os óleos lubrificantes sintéticos e semissintéticos, deixando de lado os produtos de menor lavor de mercado que são os óleos lubrificantes minerais.

O mercado de lubrificante automotivos brasileiro, é considerado um mercado bastante concorrido, haja vista a diversidade de marcas existente no mercado, que apresentam diferentes tipos de lubrificantes. Dentre os quais o mais utilizado pelos usuários de veículos são os sintéticos e os semissintéticos [1]

Os óleos lubrificantes e óleos de motor foram introduzido nos motores de combustão interna e nos sistemas de transmissão de modo que minimize principalmente o atrito dentre das engrenagens dos motores visando um melhor desempenho dos motores, desta forma evita as eventuais quebras dos componentes, tendo como principal funcionalidade a manutenção dos motores visando o aumento da oneração [2].

A prevenção com o óleo lubrificante forma uma película que impede o contato direto das peças metálicas em movimento. O motor de um carro popular utiliza em média de 3 a 4 litros de óleo lubrificante [3].

Os lubrificantes não são todos iguais, cada um tem seu componente e sua formulação, mesmo sendo do mesmo fabricante. Os lubrificantes têm bases que podem ser sintéticas, minerais ou semissintéticas (que é a mistura dessas duas), e um pacote de aditivos que varia de acordo com o desempenho do lubrificante e para que ele foi desenvolvido para atender necessidades que as montadoras e seus projetos pedem para aquele motor [4].

Os lubrificantes são caracterizados pela viscosidade, mas outras propriedades também são importantes. Óleo lubrificantes contém aditivos, que são compostos químicos adicionado em sua formula básica, o lubrificante já vem com os pacotes de aditivos que atende o desempenho para função e vem descrita na embalagem Quando é adicionado um produto que não é formulado pelo fabricante, ele pode alterar a composição química, para tanto pode levar o lubrificante a perda de desempenho e de característica [5].

Diante do cenário atual observa-se uma lacuna de conhecimentos específicos sobre os lubrificantes para motores de combustão interna e uma demanda na falta de informação quanto a utilização especifica para cada tipo de motor. Atualmente quando o usuário de veículo procura uma oficina mecânica especializada para realizar uma troca de óleo do motor, eles optam pelo lubrificante sintético ou semissintético, por que são os mais vendidos, e por sua vez usuários levam em consideração o valor do produto visando o custo e não o benefício.

O lubrificante que apresenta um rendimento de baixa qualidade possivelmente apresentará problemas futuros no motor de seu veículo, dentre outros equívocos realizados pelos usuários de veículos está voltado a falta de informação por não conhecer o
Manual do veículo, e as especificações necessárias como a mistura de lubrificantes de bases diferentes, uso de óleo incorreto, as trocas de óleo em veículos de baixa e alta rotatividades, preenchimento do nível errado do óleo lubrificante.

Diante da problemática em questão pretende-se realizar uma análise quanto ao desempenho e rendimento no uso de óleo lubrificante de base sintética e semissintética no motor do ciclo otto, através de analises físicas e de observações. Qual lubrificante tende a perder sua capacidade de lubrificação após o seu uso em um motor do ciclo otto?

No mercado bastante concorrido em qualquer segmento mundial, um número maior de lubrificantes tem surgido propondo melhores tecnologias para o usuário. Com o surgimento e crescimento da necessidade de ter um produto que tenha um custo baixo e alta qualidade, surgem também novos empregos e novos investidores para o mercado de lubrificantes.

Essa pesquisa justifica-se pela ausência, ou necessidade de um maior, ou melhor, conhecimento dos usuários de motores de combustão interna quanto da troca do óleo lubrificante, pois em alguns casos, os usuários não têm ou não detém os conhecimentos específicos sobre o uso de óleos lubrificantes sejam eles sintéticos ou não e em relação também as suas marcas, hoje existe essa divergência ao redor de todos os usuários tanto nacionais ou internacionais. Outrossim, analisar o desempenho dos lubrificantes de bases sintéticas e semissintéticas visando o melhor rendimentos em suas propriedades para que evitem prejuízos para o motor, viabilizando a vida útil do motor.

A partir dos principais equívocos ocasionados pelos usuários de veículos ao realizarem a troca do lubrificante apenas por indicação e não por conhecer seu desempenho e rendimento e principalmente pelo uso inadequado de lubrificantes.

Sendo assim, torna-se primordial a análise do desempenho dos óleos lubrificantes de bases sintéticas e semissintéticas para avaliar através de testes físicos e de observação qual dos óleos lubrificantes apresentam os melhores desempenhos e rendimentos em suas especificidades, quanto a importância do uso da lubrificação sintética e semissintética de forma adequada para o motor ciclo otto, visando evitar a manutenção corretiva precoce o motor ciclo otto.

Analisar as amostras de óleos lubrificantes sintéticos e semissintéticos utilizando ensaios de laboratório no motor ciclo otto; Identificar os principais problemas de desempenho e rendimento após o uso de óleos lubrificantes sintéticos e semissintéticos no motor ciclo otto e Apresentar índices para a escolha do óleo mais adequado para motor ciclo otto são alguns focos de estudos comparativos dos óleos sintéticos e semissintéticos para avaliar a capacidade de lubrificação desses óleos que serão tratados nessa pesquisa.

Atualmente as questões ambientais relacionados a reciclagem dos óleos lubrificantes usados que tem aumentado cada vez mais com o passar dos anos com consciência ecológica e as legislações ambientais em todo o mundo. É importante mencionar que fatores econômicos também influenciam, nos países desenvolvidos as questões de destinação do óleo e muito rigoroso e tratado como uma necessidade de proteção ambiental. 
É de fundamental importância mencionar que ,a destinação inadequada nos discastes de óleos lubrificantes usados ou contaminados polui a terra, a água e o ar, prejudicando o meio ambiente, com isso o Ministério do Meio Ambiente tem atuado muito nos setores de lubrificantes, para acompanhar o recolhimento, armazenagem, transporte e destinação final dos óleos usados ou contaminados, para atuar nas questões de lubrificantes o ministério do meio ambiente tem contado com três órgãos responsáveis pela fiscalização das distribuidoras o Grupo de Monitoramento Permanente (GMP), Associação de Entidades Estaduais do Meio Ambiente (ABEMA) e Associação Nacional de Órgãos Municipais de Meio Ambiente (ANAMMA) o objetivo desses órgãos e fiscalizar o cumprimento de metas de recolhimento de um resíduo tóxico e altamente perigoso. Além das fiscalizações o GMP organiza reuniões ordinárias e extraordinária com oficinas regionais e nacionais [4].

\section{REVISÃO BIBLIOGRÁFICA}

\section{II.1 COMPREENDENDO AS PECULIARIDADES E RELEVÂNCIA DO ÓLEO DE LUBRIFICAÇÃO}

A lubrificação é uma operação que consiste em introduzir uma substância apropriada entre superfícies sólidas que estejam em contato entre si e que executam movimentos relativos. Essa substância apropriada normalmente é um óleo ou uma graxa que impede o contato direto entre as superfícies sólidas. Quando recobertos por um lubrificante, os pontos de atrito das superfícies sólidas fazem com que o atrito sólido e um fluido. Nessas condições, o desgaste entre as superfícies será bastante reduzido [6].

Quando ocorre um movimento relativo entre superfícies, é normalmente desejável minimizar o atrito e o desgaste. Enfatizando que o óleo lubrificante interposto reduz o atrito e o desgaste dos componentes do motor. Em sistemas metálicos deslizantes típicos, o coeficiente de atrito seco pode variar em uma faixa de 0,5 a 1,0 e essa faixa pode ser reduzida por um fator $1 / 2 \mathrm{ou}$ $1 / 4$ com uso de lubrificante [7].

Os óleo lubrificante automotivo devem possuir uma série de características especiais para satisfazer as exigências mecânicas e as variações de condições operacionais e ambientais a que estarão continuamente submetidos. O desenvolvimento e a formulação de um óleo lubrificante é um trabalho complexo, em que o técnico deve estudar a compatibilidade entre os tipos de óleos básicos, entre os diversos tipos de aditivos e entre estes óleos e aditivos, de acordo com sua finalidade

\section{II.2 HISTÓRIAS DO ÓLEO LUBRIFICANTE}

Conforme [6], a mais antiga manifestação de lubrificação da qual se tem notícia foi achada no Egito, no túmulo de Ra-Em-Ka, 2600-1700 a.C.: é mostrado um tipo de trenó transportando um monumento de pedra, e um homem que despeja um líquido para lubrificar os deslizadores do trenó. Matéria graxa foi realmente encontrada no eixo de uma carruagem enterrada no tumulo de Yuaa e Thuiu, datando de cerca de 1400 a.C.

Para [6] afirmam ainda, que a história no campo petrolífero de Baku está relacionada aos adoradores do fogo que, por volta de 600 a.C., faziam peregrinações "ao fogo" proveniente de gás natural que emergia do solo. Na reserva petrolífera de Baku considerada um dos grandes campos petrolíferos da Rússia. Devese aos romanos o mais antigo registro de utilização do petróleo na iluminação. O óleo obtido em Agrigentum, na Sicília, era usado em lamparinas no templo de Júpiter. Os registros quanto a referência ao petróleo foram encontradas nos escritos gregos, conhecidos na China de 2000 anos atrás, bem como na Índia conhecido como Rangoon Oil. Os colonizadores da América do Norte descobriram que os índios usavam o petróleo como remédio para toda sorte de doenças.

A primeira notícia de destilação industrial de petróleo foi na data de 1810, em Praga, com o objetivo de obter óleo para iluminação.

De acordo com [6], foi na Inglaterra, em 1826, Hildreth, foi sugerido que o petróleo fosse usado como material de iluminação em vez de óleo de baleia. Em 1846, Gesner produziu um óleo iluminante por destilação de carvão, dando-lhe o nome de "querosene". Kier, em Pittsburgh, usou ao o petróleo destilado como iluminante a posteriori.

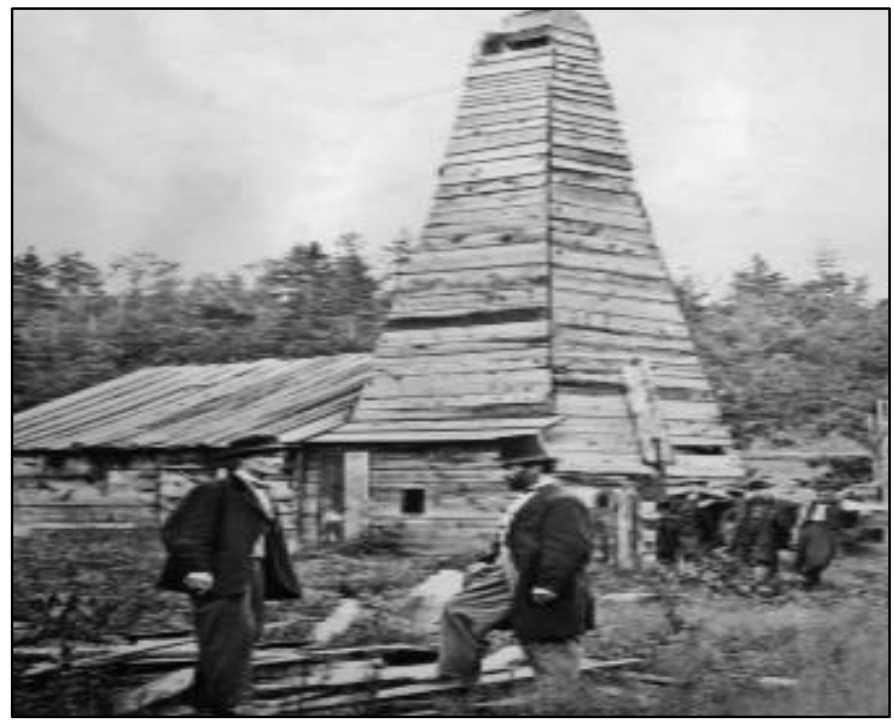

Figura 1: Primeiro poço de petróleo perfurado por Drake.

Fonte: Lubrificantes \& Lubrificação Industrial, (2006).

Segundo [6] enfatiza que Edwin Laurentine Drake foi o primeiro indivíduo que conseguiu tirar petróleo do subsolo, portando sendo recompensado por seus esforços ao perfurar, deliberadamente, um poço para encontrar petróleo, no dia 27 de agosto de 1859. O poço perfurado por Drake na Pensilvânia, com profundidade com de $691 / 2$ pés ( 21 metros) e produção diária de 840 galões (3200 litros, aproximadamente), é considerado o primeiro poço de petróleo em todo o mundo.

No que tange ao petróleo o relevante papel coube à Escócia, no século passado, no desenvolvimento da indústria e comercio do petróleo. James Young, de Kelly, nascido em 1811, se destaca em ser o primeiro a produzir, em 1848, "paraffin oil" em escala comercial, com seu sócio Meldrum. Elaborava dois tipos de óleo de parafina: um fino, para uso como burning oil utilizados combustíveis em lâmpadas, e outro pesado, para fins lubrificantes [6]. 
No Brasil a primeira concessão para prospecção e lavra de petróleo no Brasil foi outorgada em 1864, a Thomas Denny Sargent, de nacionalidade inglesa, e referia-se a uma área no município baiano de Camamu. Seguiram-se diversas outras concessões a particulares, sendo feita a primeira sondagem profunda em 1892 e 1896, em Bofete (São Paulo), por Eugênio Ferreira de Camargo, resultando apenas em água sulfurosa [6].

Os óleos lubrificantes são classificado de acordo com a Classificações "American Petroleum Institute (API)" e Society of Automotive Engineers (SAE)" e surgiu a partir da necessidade de padronização, que tanto os engenheiros da indústria automobilística como da petrolífera, pudessem disponibilizar para o consumidor produtos de fácil identificação as siglas SAE e API, são todas baseadas em normas. Atualmente diversos órgãos reguladores que classificam os lubrificantes, o produto $\mathrm{e}$ classificado por suas determinadas funções tais como, composições, características físicas, entre outros requisitos.

A classificação American Petroleum Institute (API) é a mais tradicional e indica especificação de desempenho e a classificação "Society of Automotive Engineers (SAE)" é a classificação mais antiga para lubrificantes automotivos para motor e transmissão. É relevante mencionar que a SAE define as faixas de viscosidade, não levando em consideração seu desempenho. Para tanto os óleos podem ser mono ou multiviscosos conforme a especificação que atende. Outro fator existente é que os óleos multiviscosos se identificam pela representatividade através da letra W "Winter", que tem sua tradução na língua inglesa de inverno [8].

A demanda global de lubrificantes vem crescendo em média $1 \%$ depois da crise mundial de 2009. É importante afirmar que o mercado mundial de óleos lubrificantes apresenta uma tendência por lubrificantes com maior qualidade e eficiência, essa tendência vem ocorrendo haja vista as empresas automobilísticas e de máquinas industriais desenvolverem novos equipamentos que demandam maior qualidade para garantir a proteção desses equipamentos, de determinados problemas com, por exemplo, superaquecimento e desgastes as peças [9].

O Gráfico da figura 2, apresenta a demanda de óleos lubrificantes no mundo de 2000 a 2011.

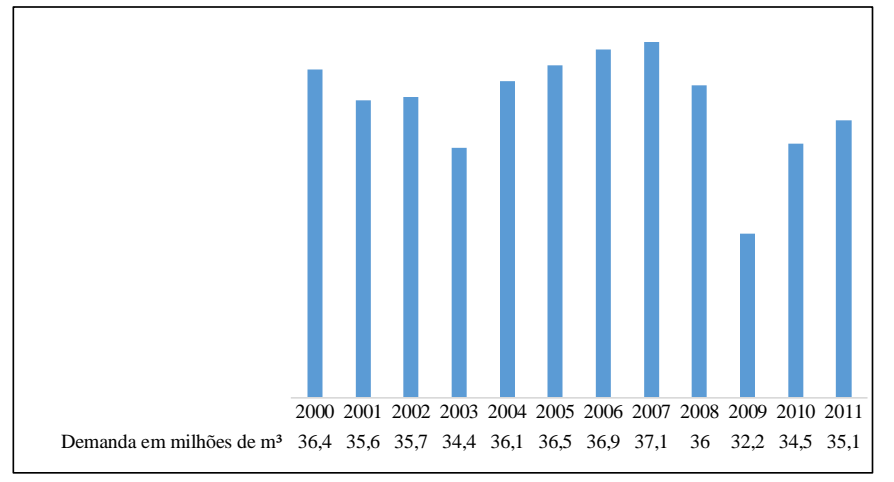

Figura 2: Gráfico da Evolução da demanda Mundial de óleo lubrificante.

Fonte: [10].

A demanda de óleos lubrificantes industriais e automotivos, por consequiência diversa movimenta uma variação de mercado mundial de óleo lubrificantes, no início do século XXI, podemos observar conforme no gráfico 1, que no período de 2000 a 2011, a demanda sofreu variações, a mais clara foi no ano de 2009 devido à crise econômica mundial, que se iniciou nos estados afetando o mercado mundial em diversos setores da indústria global conforme [10].

A figura 2 mostra a evolução da demanda de óleo lubrificante no Brasil no período de 2000 a 2015.

Enfatizando o mercado brasileiro de óleo lubrificante cresceu muito no decorrer dos anos, foi impactado no de 2015 por 3 importantes fatores que foram Crise política, Crise econômica, Os níveis mínimos de qualidade) com a resolução n²2/2014 publicada em 14 de Abril de 2014 a Agencia Nacional do Petróleo e Biocombustíveis - ANP estabeleceu critérios mínimos de qualidade para todos os fornecedores do mercado brasileiro da seguinte forma: API SJ ou ACEA-2012 para o ciclo Otto e API CG-4 ou ACEA-2012 para o ciclo Diesel.

Os prazos da primeira etapa entraram em vigor dia 31/12/2012 com isso, os níveis mais baixos e mais baratos API SF e CF foram banidos para o uso automotivo, e suas produções e importações proibidas a partir de janeiro de 2015 [6].

Segundo [6] afirma que o mercado brasileiro de lubrificante no ano de 2015 movimentou um montante aproximado de $\mathrm{R} \$ 20,4$ milhões e com um volume final entorno de 1,375 milhões de metros cúbicos de óleo lubrificantes, que se divide em $72 \%$ para o seguimento automotivo e $28 \%$ para o industrial, conforme figura 3.

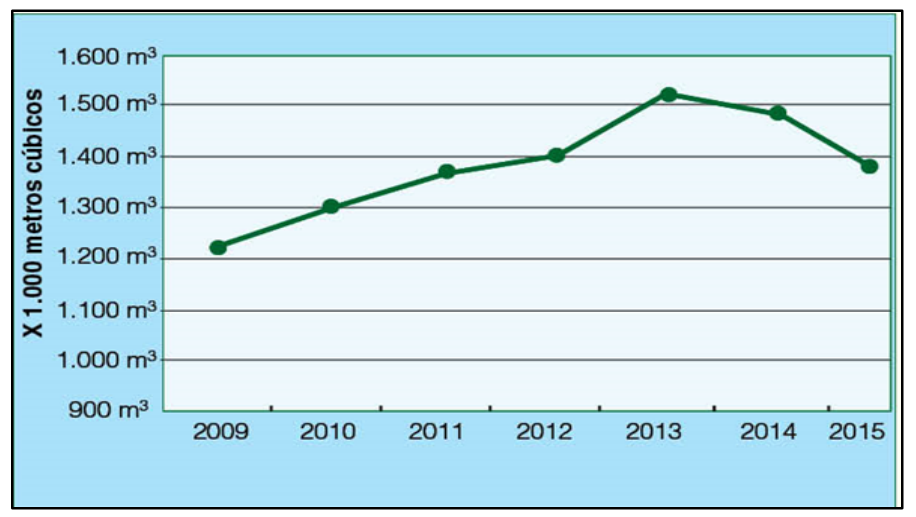

Figura 3. Volume em metros cúbicos $x$ anos.

Fonte: [6].

\section{II.3 FUNÇÃO E BASES DOS LUBRIFICANTES AUTOMOTIVOS}

\section{II.3.1 PRINCIPAIS FUNÇÕES DO ÓLEO LUBRIFICANTE}

De acordo com [11] cita um conjunto com as principais funções do óleo lubrificante, abaixo enumeradas:

$>$ Controle de atrito: A função primaria do óleo lubrificante e formar uma película volumosa entre duas superfícies que impede o contado direto, reduzindo o atrito e os desgastes que podem levar a quebra dos componentes do motor.

$>$ Controle de temperatura: O óleo lubrificante também é responsável pela refrigeração do motor, por meio da 
transferência de calor, o calor é transferido para o óleo através do seu contato com os diversos componentes do motor, e então, o óleo e encaminhado para o sistema de arrefecimento de óleo.

$>$ Limpeza: Em motores de combusto interna especialmente, uma das principais funções do óleo lubrificante é retirar as partículas resultantes do processo de combustão e manter as partículas em suspenção no óleo, evitando que se depositem no fundo do cárter e provoquem incrustação.

$>$ Proteção contra corrosão: A corrosão e o deste podem resultar na remoção de metais do motor, por isso a importância dos anticorrosivos e ante desgaste.

$>$ Vedação da câmara de combustão: O lubrificante ao mesmo tempo que lubrifica e refrigera, também age como agente de vedação, impedindo a saída de lubrificantes e a entrada de contaminantes.

$>$ Aumentar as funções dos óleos lubrificantes é importante para o melhor desemprenho do motor, muitos produtores de óleos lubrificantes buscam essas melhorias em pesquisas, e são criados diversos aditivos para o melhoramento dessas propriedades.

\section{II.3.2 BASES DOS ÓLEOS LUBRIFICANTES}

Segundo [6] as bases são as principais constituintes dos lubrificantes. Na sua maioria tem como origem do petróleo, as bases são combinadas com aditivos especiais que lhe conferem as propriedades químicas ou físicas adicionais. As bases dos lubrificantes são obtidas do refino do petróleo cru. Atender ás necessidades de qualidade da indústria automobilística a API nos Estados Unidos e a Association Techninique de L' Industrie Europeanne des Lubrifiants (ATIEL) na Europa adotaram um sistema de classificação, com a principal finalidade de patronizar as especificações dos óleos básicos para todas as refinarias existentes no mundo, se tornaram um parâmetro principal, são eles, Teor de Enxofre, Teor de Saturados e o Índice de Viscosidade, os grupos foram classificados das seguintes formas distribuído em grupos que são:

$>$ GRUPO I: Teor de Enxofre maior que 0,03\%, Teor de saturados menor que $90 \%$ e o índice de viscosidade situado entre 80 e 120.

$>$ GRUPO II: Os óleos classificados nesse grupo já, receberam um tratamento com hidrogênio que coloca o teor de Enxofre menor que $0,03 \%$ e o teor de saturados maior que $90 \%$, mas o Índice de viscosidade continua entre 80 e 120.

$>$ GRUPO III: Com um tratamento mais severo com hidrogênio e um processo de isomerização, o Índice de viscosidade é elevado acima de 120 , continuando o Enxofre com o teor abaixo de $0,03 \%$ e o teor de saturados acima de $90 \%$.

$>$ GRUPO IV: Neste grupo foram colocados todas as Polialfaolefinas (PAO's).

$>$ GRUPO V: Os outros óleos sintéticos que não estão enquadrados nos outro grupos, como os ésteres, poliglicóis etc,
$>$ GRUPO VI: Foi criado exclusivamente para abrigar um tipo de oligômero de óleo fina fabricado na Europa, chamado de Polialfaolefinas (PIO's), afim de simplificar os processos de aprovação.

\section{II.3.3 ÓLEOS DE BASES SINTÉTICAS}

Dentro deste contexto [6] afirma que com a evolução dos motores cada vez mais potentes, os óleos lubrificantes minerais já não atendiam as exigências das montadoras quanto à viscosidade, que exigiu dos fabricantes a criação de um lubrificante mais resistente em altas temperaturas, criado em laboratório, a partir de outros elementos químicos não existentes no petróleo. É de suma relevância destacar que estes óleos possuem uma curva de viscosidade mais constante, independente da temperatura e funcionamento do motor, evitando a carbonização do mesmo. Entretanto indicado principalmente para motores de alta performance, o uso do óleo lubrificante de base sintética pode proporcionar o aumento da vida útil do motor e maior desempenho, garantido a lubrificação superior à dos minerais.

Algumas das vantagens técnicas dos lubrificantes de bases sintéticas podem ser descritas como resistências a alta temperatura extremas e suas variações, melhor resistência a oxidação, maior vida útil com consequente a redução do desgaste o óleo usado, o preço do óleo lubrificante de base sintética é mais elevando em comparação aos óleos lubrificantes de bases mineral [12].

Os principais óleos sintéticos usado atualmente no mercado podem ser classificados nos seguintes grupos:

$>$ Oligômeros de Olefina (PAO's ou Palialfaolefinas): São as bases sintéticas mais usadas na formulação de lubrificantes, feitas a partir da combinação de duas ou mais moléculas de deceno em oligômeros ou polímeros polímeros de cadeia curta, tratados com Hidrogênio a alta pressão.

> Ésteres de Ácidos Diásicos: São caracterizados por excelentes propriedades à baixa temperatura, estabilidade ao calor, boa estabilidade térmica e oxidação, alto IV, e boas características em manter em suspenção os materiais formadores de depósitos, superiores ao óleo de petróleo, na sua reação viscosidade-temperatura menos voláteis.

> Ésteres de Organofostatos: Têm um poder lubrificante muito alto e não são inflamáveis como os óleos de petróleo, sua volatilidade é baixa e sua relação viscosidade-temperatura é ligeiramente melhor que a dos óleos de petróleo.

> Ésteres de Silicatos: Este composto possui qualidade de baixa volatilidade e relação entre viscosidadetemperatura que os colocam entre os melhores sintéticos, entretanto sua estabilidade térmica e hidrotérmica deixam a desejar.

> Silicones: o nome de silicone é empregado para designar fluidos que são polímeros de metil-siloxano, polímeros de fenil-siloxano ou polímeros de metil-fenil-siloxano. O aumento do teor de fenil aumenta a estabilidade ao calor, mas diminui o índice de viscosidade, embora permaneça sempre acima do nível dos óleos de petróleo. 
$>$ Compostos de Ésteres de Poliol (POE ou Poliol éster): Os Poliol ésteres têm sido usado usados como lubrificantes em diversas aplicações e também são utilizados como fluidos hidráulicos especiais.

> Politubutenos ou Poliisobutilenos: São butenos ou isobutilenos polimerizados, podem ser utilizados como espessastes e matéria prima para aditivos. Também como base de óleo para laminação de metais, cabo de aço engrenagens e outros.

$>$ Poliglicóis (Polialquilenoglicóis ou PAG): São polímeros sintetizados a partir de óxidos de etileno e de propileno, normalmente disponível em grande variedade de viscosidade.

$>$ Alquilados Aromáticos: São obtidos a partir da reação de um núcleo aromático, possui características similares às PAO's, mas com algumas limitações nas aplicações nas faixas de viscosidade, são utilizados como bases sintéticas apara lubrificantes automotivos e industriais.

\section{II.3.4 ÓLEO LUBRIFICANTE SEMISSINTÉTICO}

Os óleos semissintéticos são uma mistura balanceada de óleos básicos minerais convencionais e óleos em sua composição $100 \%$ sintecos. Esses óleos lubrificantes são recomendados para motores mais potentes que os motores que usam óleo lubrificantes minerais, e que atingem um nível de rotação acima da média [13].

\section{II.4 TESTES DE ANÁLISE DE LUBRIFICANTES}

\section{II.4.1 TESTE DE VISCOSIDADE DO ÓLEO LUBRIFICANTE}

A viscosidade é uma propriedade física importante que deve ser melhorada e controlada cuidadosamente, essa propriedade do óleo lubrificante é muito importante para vida útil do motor. Normalmente a viscosidade do óleo lubrificante diminui com a temperatura, a muitos aparelhos que podem medir a viscosidade no local da retirada do óleo lubrificante, entretanto para ter uma melhor analise, a amostra de óleo lubrificante deve ser enviada para o laboratório. Analisando a viscosidade de um óleo lubrificante permite obter importantes informações sobre o funcionamento de um motor. Outro aspecto levado em consideração é que a viscosidade pode ser afetada por fatores físicos que são os contaminantes e por fatores químicos que provem de oxidação das peças internas do motor [14][7].

Para [6], afirma que existe diferentes métodos para medir viscosidade, as conversões são feitas mediante a uma tabela, a uma determinada temperatura. Para conversão aproxima de um sistema de viscosidade a outro a mesma temperatura, usa-se os seguintes fatores de multiplicação, ilustrados na tabela 1 .

A tabela 1 indica os fatores de conversão de viscosidade segundo [6].
Tabela 1: Tabela de fatores de multiplicação de conversão de viscosidade.

\begin{tabular}{l|l|l}
\hline Cinemática (cSt) & 0,1316 & Grau Engler \\
\hline Graus Engler & 7,599 & Cinemática (centistokes) \\
\hline Graus Engler a $20^{\circ} \mathrm{C}$ & 35,106 & $\begin{array}{l}\text { Seg. Saybolt Universal a } \\
20^{\circ} \mathrm{C}\end{array}$ \\
\hline Graus Engler a $50^{\circ} \mathrm{C}$ & 35,173 & $\begin{array}{l}\text { Seg. Saybolt Universal a } \\
50^{\circ} \mathrm{C}\end{array}$ \\
\hline Graus Engler a $100^{\circ} \mathrm{C}$ & 35,353 & $\begin{array}{l}\text { Seg. Saybolt Universal a } \\
100^{\circ} \mathrm{C}\end{array}$ \\
\hline $\begin{array}{l}\text { Seg. Saybolt Universal } \\
\text { a } 40^{\circ} \mathrm{C}\end{array}$ & $\begin{array}{l}0,0284 \\
8\end{array}$ & Grau Engler $40^{\circ} \mathrm{C}$ \\
\hline $\begin{array}{l}\text { Seg. Saybolt Universal } \\
\text { a } 100^{\circ} \mathrm{C}\end{array}$ & 0,0282 & Grau Engler a $100^{\circ} \mathrm{C}$ \\
\hline
\end{tabular}

Fonte: [6].

Para fazer essa conversão aproximada foi utilizada os dados da tabela 7 de fatores de multiplicação de conversão de viscosidade, primeiro a viscosidade com sua temperatura respectiva será transformada de Saybolt para Graus Engler e depois para Centistokes, por que não a transformação. A equação utilizada está abaixo;

Para $40^{\circ} \mathrm{C}$

(Seg. Saybolt a $\left.40^{\circ} \mathrm{C}\right) \times 0,02848=$ Graus Engler $40^{\circ} \mathrm{C}$

(Graus Engler) x 7,599= Cinemática (centistokes)

Para $100^{\circ} \mathrm{C}$

(Seg. Saybolt a $\left.100^{\circ} \mathrm{C}\right)$ x 0,02829 = Graus Engler $100^{\circ} \mathrm{C}$

(Graus Engler) x 7,599 = Cinemática (centistokes)

Para obter o grau de viscosidade SAE, os resultados da análise de viscosidade cinemática em centistokes dos óleos usados serão comparados com a tabela SAE, assim teremos o grau de viscosidade SAE para os óleos usados. A importância desse resultado, servira para fazer uma analisar do comportamento dos óleos lubrificantes após seu uso.

Segundo [6], o índice de viscosidade é o método mais usado para expressar o relacionamento da viscosidade com a temperatura. A análise de índice de viscosidade é normatizada pela NBR 14358 e ASTM D2270, para se determinar o IV - em inglês viscosity index, na sua tradução para o português índice de viscosidade, de um óleo a uma viscosidade a $100^{\circ} \mathrm{C}$, e calculado partindo de sua viscosidade a $40^{\circ} \mathrm{C}$. A equação utilizado é do cálculo de índice de viscosidade de Dean Davis, que é de uso correto no Estados Unidos e no Brasil.

Equação Dean Davis para calcular o índice de viscosidade de um óleo.

$$
I V=\frac{L-U}{L-H} X 100
$$

Viscosidade a $40^{\circ} \mathrm{C}$ de um óleo de índice de viscosidade 0 , tendo a mesma viscosidade a $100^{\circ} \mathrm{C}$ do óleo em estudo. 
$\mathrm{H}=$ viscosidade a $40^{\circ} \mathrm{C}$ de um óleo de índice de viscosidade 100 , tendo a mesma viscosidade a $100^{\circ} \mathrm{C}$ do óleo em estudo

$\mathrm{U}=$ viscosidade $\mathrm{a} 40^{\circ} \mathrm{C}$ do óleo em estudo.

\section{II.4.2. TESTE DE CONTAMINAÇÃO POR ÁGUA}

O aparecimento de água no óleo lubrificante é sempre indesejável, devido aos diversos problemas ocasionar no motor e pelo elevado custo decorrente. O motor trabalhando, em períodos curtos, e temperatura abaixo do normal, facilita a contaminação de água no óleo lubrificante, que pode acelerar o desgaste dos anéis de seguimento dos cilindros. Consequentemente o excesso de contaminação por água poderá ocasionar problema nos filtros de óleo, a presença de água é também uma das responsáveis pela oxidação do tanque se estocagem de óleo lubrificante, a sua presença especificamente é determinada através da soma óbitos nos ensaios de água por destilação e sedimento por extração [15].

\section{MATERIAIS E MÉTODOS}

\section{III.3 COLETA DA AMOSTRA DOS ÓLEOS LUBRIFICANTES}

A referente pesquisa é uma análise de dois tipos de óleos lubrificantes automotivos, que são o sintético e o semissintético, esses óleos lubrificantes foram utilizados em um mesmo veículo de alta rotação, cada lubrificante foi utilizado por 5.000 quilômetros, que é especificado no manual do veículo o recomendado para veículos de alta rotação, este veículo é um Gol do modelo.

Em laboratório foram feitas analises físicas de viscosidade cinemática, índice de viscosidade e crepitação do óleo, para identificar contaminação por água, os testes foram feitos com lubrificantes usados e novos.

O veículo rodou com o lubrificante sintético de 155.000 a 160.000 quilômetros, já com o semissintético rodou de 160.000 a 165.000 quilômetros, dada lubrificante rodou 5.000 quilômetros, que é o recomendado no manual do veículos para veículos com alta rotação.

Foram utilizados os testes ensaios físicos de viscosidade cinemática, índice de viscosidade e contaminação por água. Os testes de viscosidade cinemática de $40^{\circ} \mathrm{C}$ e $100^{\circ} \mathrm{C}$, são normatizados pela norma ASTM D445 e NBR 10441, o teste de índice de viscosidade é normatizado pela norma ASTM D2270 e NBR 14358. Para o teste de contaminação por água foi utilizado o teste de crepitação do óleo. Os óleos lubrificantes utilizados foram, da marca Shell, semissintético 10W-40, sintético 5W-40.

Conforme a especificação emitida no verso da embalagem o óleo Shell hx7 5w-40 e utilizado em veículos de injeção eletrônica, sistema de recirculação dos gases de combustão e conversores catalíticos, movidos a gasolina, etanol, diesel, GNV ou veículos com motor flex. O Shell Helix HX7 foi formulado com tecnologia especial de limpeza ativa, previne contra a formação de sujeiras e o acumulo de fuligem do motor, para uma condução segura até a próxima troca de óleo do motor.

Para fazer o teste de viscosidade foi utilizado um viscosímetro "Saybolt", da marca Quimis, modelo Q288SR24.
Segundo a especificação emitida no verso da embalagem ó óleo Shell Helix Ultra é utilizado em veículos com injeção eletrônica e recirculação de gases de combustão e conversores catalíticos que operam em qualquer condição de uso.

O Shell Helix Ultra foi formulado com tecnologia especial de limpeza ativa, previne contra a formação de sujeiras e o acumulo de fuligem do motor, para uma condução segura até a próxima troca de óleo do motor. Na figura 7 , apresenta-se um viscosímetro s"aybolt", marca Quimimis, modelo tal utilizado nos testes de viscosidade cinemática.

Segundo [6] afirmam que, a medição pelo aparelho "Saybolt" (ASTM D-88), a viscosidade é indicada pelo tempo, em segundos, necessário para que $60 \mathrm{~cm}^{3}$ de óleo escorra completamente por um orifício de $1,765 \mathrm{~mm}$ de diâmetro, sob ação da gravidade, a uma determinada temperatura.

\section{RESULTADOS E DISCUSSÕES}

Testes com óleos lubrificantes usados a $40^{\circ} \mathrm{C}$ e $100^{\circ} \mathrm{C}$

A análise viscosidade cinemática com óleos lubrificantes usados está normatizado pela NBR 10441 e pela ASTM D445. Nessa análise foram utilizadas amostras de óleo lubrificante semissintético e sintético usados com uma rotação no veículo de 5.000 quilômetros, cada amostra contém uma quantidade de $60 \mathrm{ml}$. A figura XX apresenta as amostras de óleos lubrificantes sintéticos e semissintéticos usados, que foram utilizados para fazer o testes de viscosidade.

Os resultados obtidos com o lubrificante semissintético usado aquecido a $100^{\circ} \mathrm{C}$ são: o escoamento dos óleos durou 93,9 segundos Saybolt para o óleo semissintético enquanto que com o óleo sintético o escoamento durou 121,4 segundos Saybolt. Esses resultados foram comparados com a tabela de viscosidade à mesma temperatura, para obter o valor em cSt - "Centistokes" que é o grau de viscosidade cinemática.

Os testes de viscosidade cinemática para óleos lubrificantes a $40^{\circ} \mathrm{C}$ é normatizado pela ABNT 10441 e pela ASTM D2270. Os resultados obtidos com os óleos lubrificantes aquecidos a $40^{\circ} \mathrm{C}$ foram os seguintes: Os óleos lubrificantes tipo Semissintético, seu escoamento durou 421, 10 segundos "Saybolt", já o sintético teve um escoamento de 394,10 segundos "Saybolt", esses resultados serão comparados a tabela de viscosidade à mesma temperatura para obter o seu valor em cSt, que é o grau de viscosidade cinemática. A figura 4 exibe os óleos lubrificantes utilizados nesse estudo.

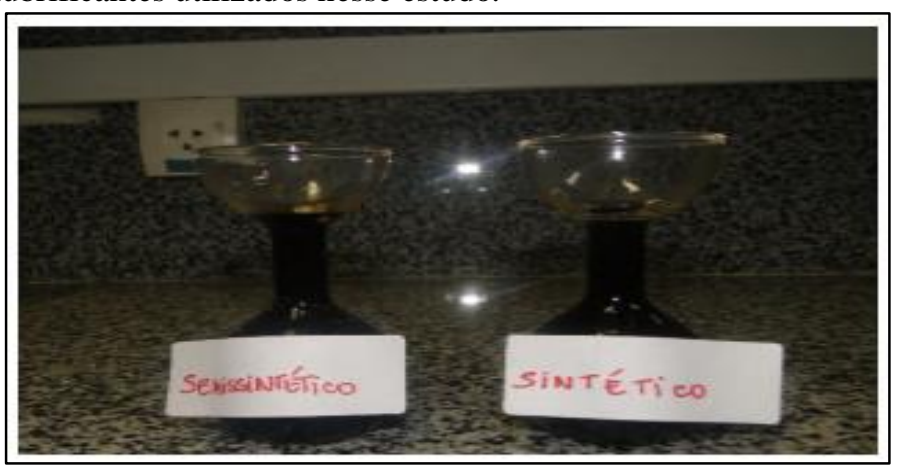

Figura 4: Amostras de óleos lubrificantes usados.

Fonte: Autores, (2016). 
As amostras foram introduzidas no viscosímetro Saybolt, e o viscosímetro foi programado para aquecer o lubrificante até $100^{\circ} \mathrm{C}$. A figura 5 mostra os testes de viscosidade sendo realizados em laboratório.

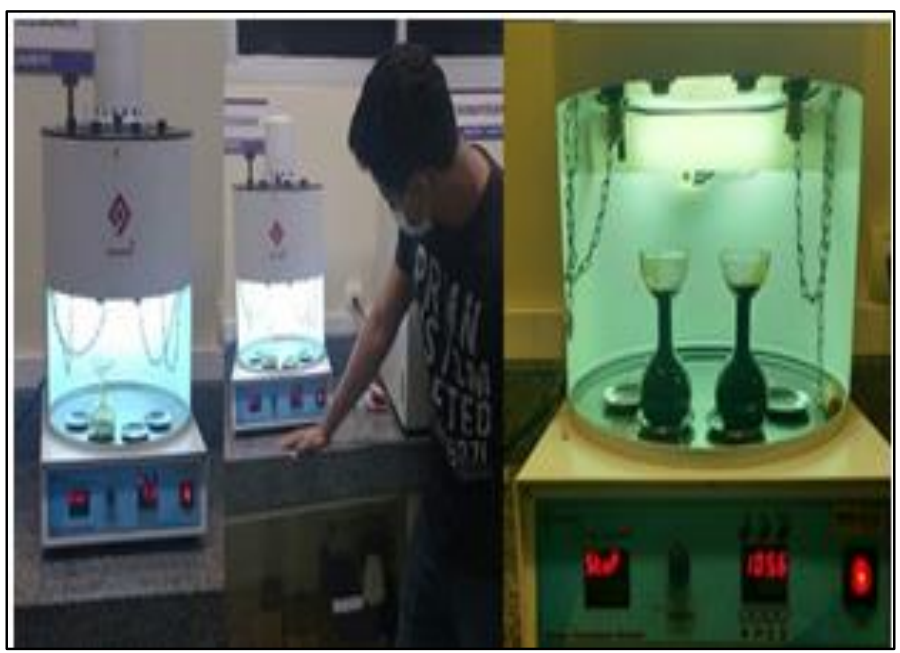

Figura 5: Análise dos óleos lubrificantes usados.

Fonte: Autores, (2016).

Testes com óleos lubrificantes novos a $40^{\circ}$ e $100^{\circ} \mathrm{C}$

O teste físico de viscosidade cinemática para óleos novos esta normatizado pela NBR 14358 e pela ASTM D2270. Para os testes com óleos lubrificantes novos também foi utilizado o viscosímetro Saybolt, os testes são a $40^{\circ} \mathrm{C}$ e $100^{\circ} \mathrm{C}$. A figura 10 exibe os testes de viscosidade sendo realizados com os óleos lubrificantes novos.

A figura 6 mostra o processo de análise em laboratório.

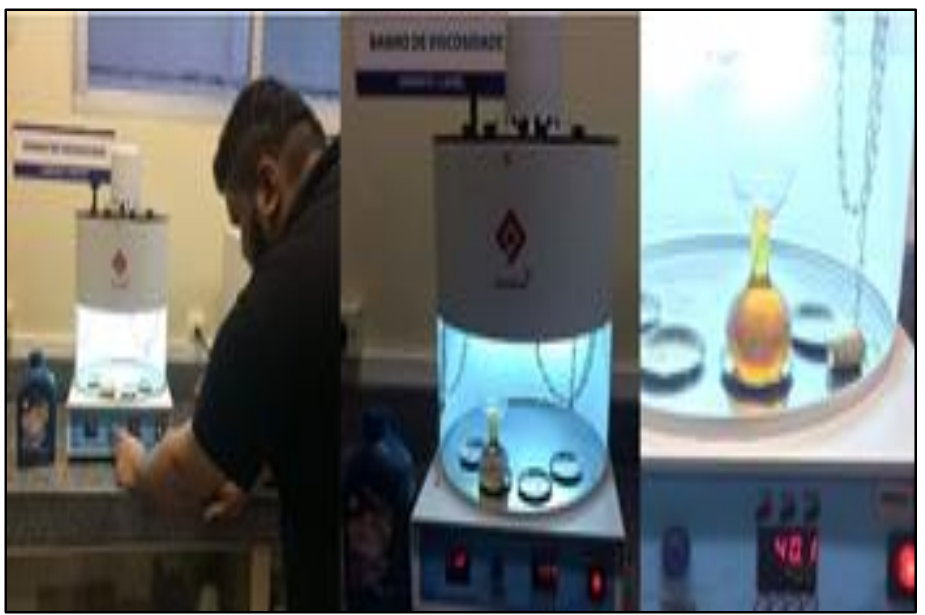

Figura 6: Análise dos óleos lubrificantes novos.

Fonte: Autores, (2016).

Os testes de viscosidade cinemática com óleos lubrificantes semissintético e sintético novos aquecido a $100^{\circ} \mathrm{C}$, foram os seguintes resultados obtidos, para óleo semissintético novo o seu escoamento durou 93,4 segundos Saybolt, entretendo o lubrificante sintético novo seu escoamento durou 94,9 segundos
Saybolt, esses dados serão comparados a tabela de viscosidade à mesma temperatura para se obter o seu valor em Centistokes, a seguir os resultados serão comparados com a tabela SAE, apara se obter o grau de viscosidade SAE.

Os testes de viscosidade cinemática com óleos lubrificantes semissintéticos e sintéticos novos aquecidos a $40^{\circ} \mathrm{C}$, foram obtidos os seguintes resultados, o escoamento do óleo semissintético novo durou 369,3 segundos Saybolt, já o sintético novo o seu escoamento durou 374,7 segundos Saybolt.

Para ter o valor em viscosidade cinemática esses resultados serão comparados a tabela de viscosidade a mesma temperatura para se obter o seu valor em Centistokes que é o grau de medida para viscosidade cinemática. A tabela 2 mostra o resultado das análises para tal transformação utilizou-se as equações 1, 2, 3 e 4 . A tabela 2 apresenta os óleos e suas temperaturas, tempo e cinemática.

Tabela 2: óleos e suas temperaturas, tempo e cinemática.

\begin{tabular}{l|c|c}
\hline $\begin{array}{c}\text { Óleos Lubrificantes e sua } \\
\text { temperatura em }\end{array}$ & $\begin{array}{c}\text { Seg. } \\
\text { Saybolt } \\
\text { SSU }\end{array}$ & $\begin{array}{c}\text { Cinemática } \\
\text { (Centistokes) } \\
\text { cSt }\end{array}$ \\
\hline Sintético novo a $40^{\circ} \mathrm{C}$ & 374,7 & 81,08 \\
\hline Sintético usado a $40^{\circ} \mathrm{C}$ & 394,1 & 85,26 \\
\hline Sintético novo a $100^{\circ} \mathrm{C}$ & 93,9 & 20,13 \\
\hline Sintético usado a $100^{\circ} \mathrm{C}$ & 121,4 & 26,06 \\
\hline Semissintético novo a $40^{\circ} \mathrm{C}$ & 369,3 & 79,86 \\
\hline Semissintético usado a $40^{\circ} \mathrm{C}$ & 421,1 & 91,12 \\
\hline Semissintético novo a $100^{\circ} \mathrm{C}$ & 93,4 & 20,06 \\
\hline Semissintético usado a $100^{\circ} \mathrm{C}$ & 93,9 & 20,13 \\
\hline
\end{tabular}

Após a análise dos óleos lubrificantes usados a $100^{\circ} \mathrm{C}$, os resultados obtidos são transformados de segundos Saybolt para Centistokes, são comparados a tabela SAE, o óleo lubrificante semissintético usado com um valor de $20,13 \mathrm{cSt}$, e o sintético com um valor de 26,06. Comparado com a tabela SAE o óleos lubrificante semissintético usado tem o grau de viscosidade SAE de 50, e o sintético tem o grau SAE de 60, o grau SAE, especificado na embalagem dos óleos lubrificantes sintéticos e semissintéticos é 40

O gráfico a figura 7 mostra os resultados da viscosidade cinemática, apresenta os seguintes resultados, os óleos lubrificantes semissintéticos, depois de usados sua viscosidade cinemática tem uma elevação de 3,47\%. Entretendo o óleo lubrificante sintético tem uma elevação na sua viscosidade de $29,45 \%$

Esses resultados apontoam de que depois do uso, os óleos lubrificantes sintéticos tem um aumento considerável no seu grau de viscosidade, enquanto os semissintéticos mantêm reativamente a sua viscosidade.

A figura 7 mostra a viscosidade cinemática a $100^{\circ} \mathrm{C} \mathrm{em}$ cSt (Centistokes). 


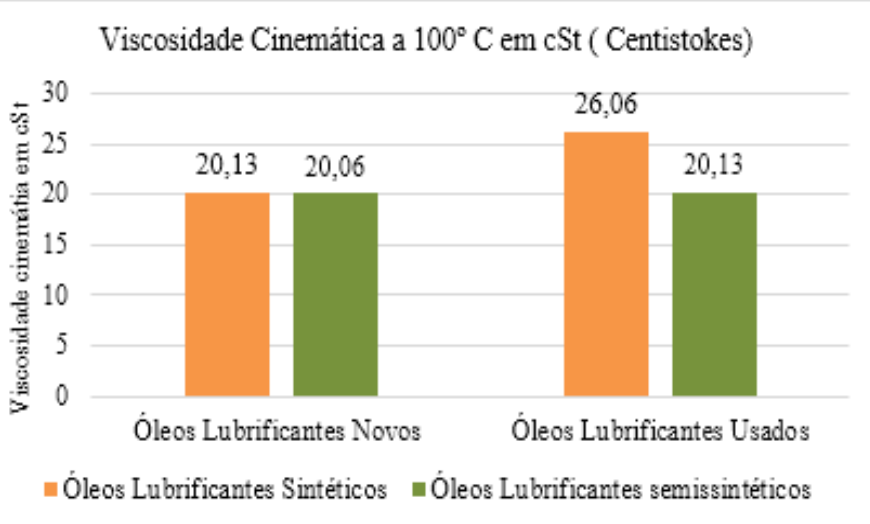

Figura 7:Viscosidade Cinemática a $100^{\circ} \mathrm{C}$.

Fonte: Autores, (2016).

O gráfico da figura 8, mostram os resultados da análise de viscosidade cinemática dos óleos lubrificantes, sintéticos e semissintéticos, novos e usados aquecidos a $40^{\circ} \mathrm{C}$.

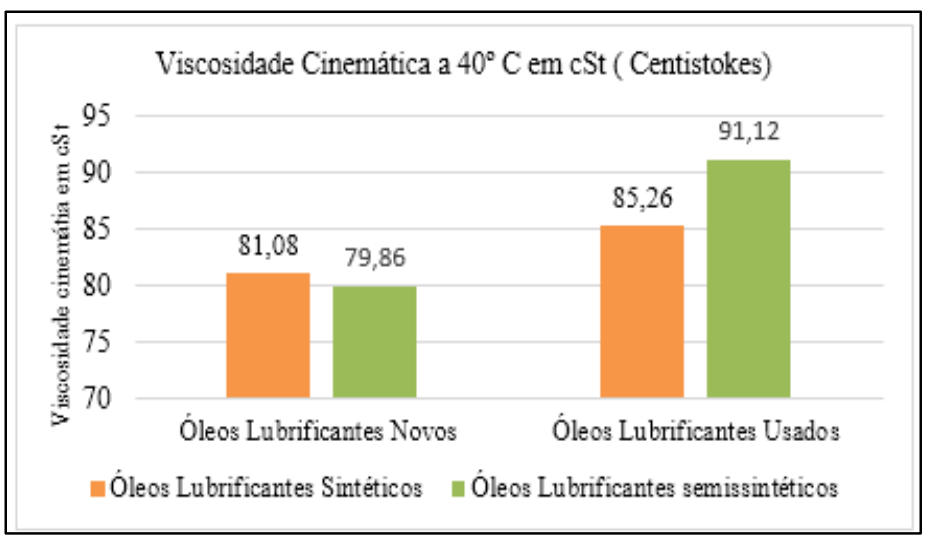

Figura 8:Viscosidade Cinemática a $100^{\circ} \mathrm{C}$.

Fonte: Autores, (2016).

Os resultados expressos no gráfico de viscosidade cinemática dos óleos lubrificantes aquecidos a $40^{\circ} \mathrm{C}$, aponta que o óleo lubrificante sintético tem um crescimento de $5,15 \%$, todavia o óleo lubrificante semissintético tem um crescimento de 14,09\% em sua viscosidade cinemática. $\mathrm{O}$ crescimento da viscosidade cinemática do óleo lubrificante semissintético e superior do que a do sintético na análise de $40^{\circ} \mathrm{C}$.

Com os resultados obtidos por meio dos cálculos de índice de viscosidade elabora-se um gráfico para a melhor identificação dos índices de viscosidades dos lubrificantes sintéticos e semissintéticos, usados e novos. Gráfico 5 demonstra os índices de viscosidades dos óleos lubrificantes sintéticos e semissintéticos, usados e novos.

O gráfico da figura 9 mostra a análise dos índices de viscosidade dos óleos lubrificantes

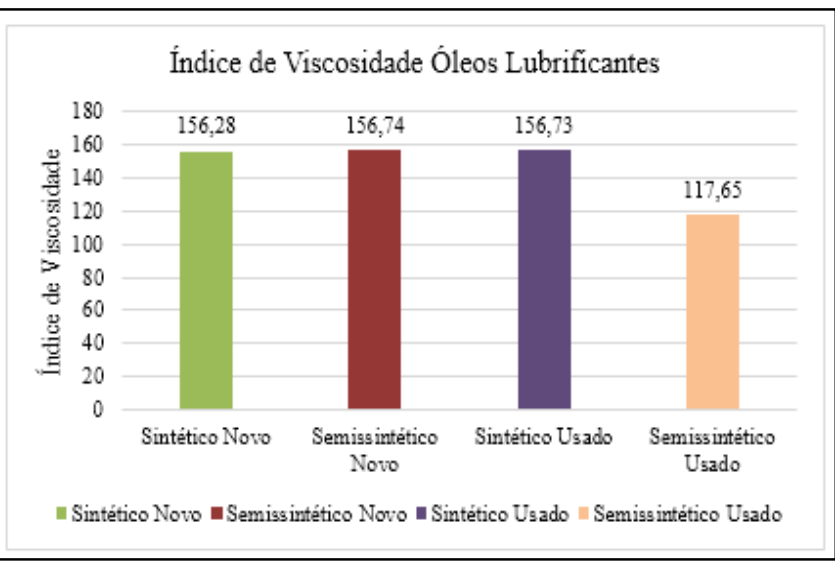

Figura 9: Análise dos índices de viscosidade dos óleos lubrificantes.

Fonte: Autores, (2016).

Os resultados obtidos com a comparação dos índices de viscosidade dos óleos lubrificantes, destaca-se que o lubrificante sintético, cresce $0,28 \%$ no seu índice de viscosidade depois do uso, portanto o lubrificante semissintético em uma perda significativa de $-24,93 \%$ do seu índice de viscosidade no lubrificante usado.

\section{IV.8 TESTE DE CONTAMINAÇÃO POR ÁGUA}

Para se comprovar a contaminação por água no óleo lubrificante usado sintético e semissintético foi utilizado o teste de crepitação do óleos lubrificante por chapa quente.

Para fazer a análise foi usada uma pipeta volumétrica com $1 \mathrm{ml}$ de cada amostra de lubrificante usado, observou-se que o lubrificante semissintético usado destacado em vermelho, teve uma maior crepitação, isso destaca que essa amostra tem contaminação de água. O óleo lubrificante sintético destacado em azul, tem uma menor crepitação, isso demonstra que foi menos afetada por contaminantes externos. A figura 12 exibe o teste feito em uma chapa aquecedora redonda da marca QUIMIS.

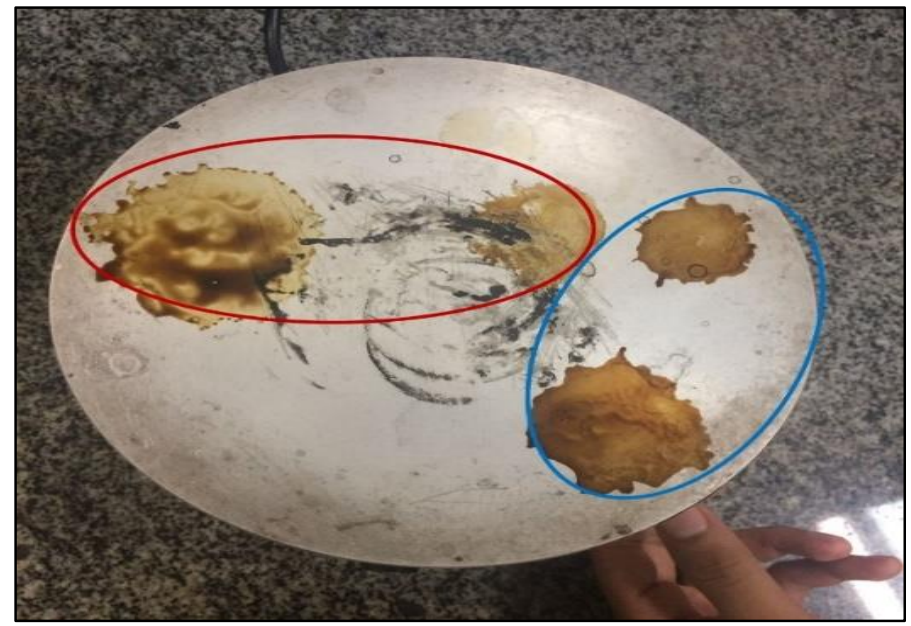

Figura 10: Amostras de óleos lubrificante sintético e semissintético analisado na chapa aquecedora.

Fonte: Autores, (2016). 


\section{IV.8 ANÁLISE DE FILTRAGEM DO ÓLEO LUBRIFICANTE SINTÉTICO E SEMISSINTÉTICO USADOS.}

A análise de observação visual por filtragem das amostras dos óleos lubrificantes usados, se utiliza para termos uma observação visual do comportamento do óleo lubrificante sintético e semissintético, com essa comparação de filtragem podemos observar qual a coloração do óleo lubrificante após seu uso. Para fazermos essa filtragem foi utilizado 2 erlenmeyer de $1000 \mathrm{ml}, 2$ funis de vidro, dois filtros de papel, se utilizou duas amostras de óleos lubrificantes usados cada uma contendo $50 \mathrm{ml}$, uma sintético e a outra semissintético. A figura 11 exibe o resultado das filtragens dos óleos lubrificantes usados.

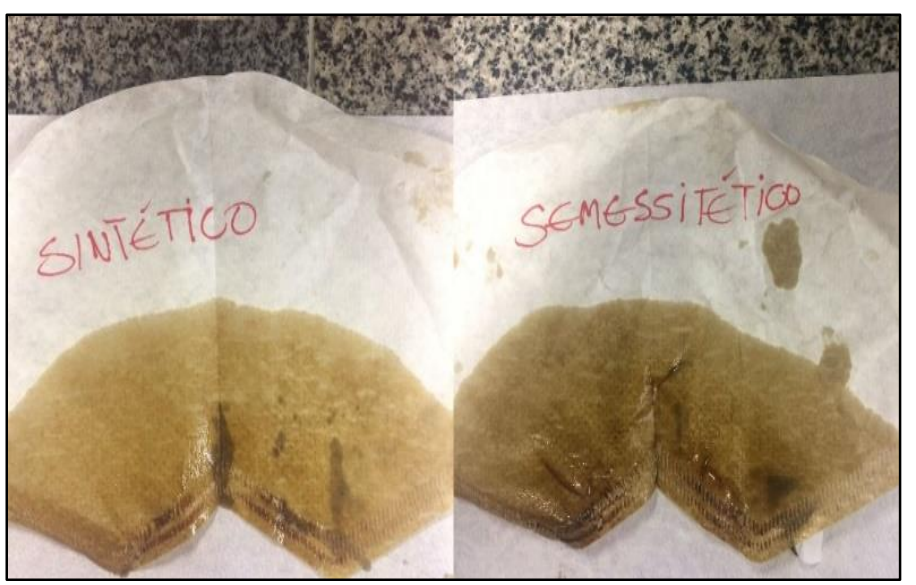

Figura 11: Amostra de óleo lubrificantes usados filtrados Fonte: Autores, (2016).

As amostras do papel filtrado revelam que o óleo lubrificante semissintético é mais escuro do que a amostra do óleo lubrificante semissintético, esse aspecto é por conta da composição do óleo lubrificante semissintético, que tem $50 \%$ de óleo mineral, com a sua queima ele se forma borras e ele tende a ficar com uma tonalidade mais escuro. O óleo lubrificante semissintético com a sua queima forma borras que gerar problemas futuros nos componentes internos do motor como o mais frequente que é a formação de crostas nos componentes internos do motor. Com essa análise observou-se que o óleo lubrificante sintético tem menos concentração de borras em relação ao semissintéticos.

\section{V.CONCLUSÃO}

Ao término dessa pesquisa concluímos que essa pesquisa exploratória descritiva teve como objetivo, realizar um estudo comparativo dos óleos lubrificantes sintético e semissintético e suas capacidades de lubrificação. Com a finalidade de identificar qual o óleo lubrificante tende a perder a sua capacidade de lubrificação, após a sua utilização em motor. Portanto, para a realização deste estudo se fez necessário a utilização de um veículo automotivo, da marca Gol City G5 2014, o óleo sintético utilizado no motor foi Shell Helix Ultra 5W-40 e o semissintético Shell Helix HX7 10W-40, os dois óleos lubrificantes tem o mesmo grau de viscosidade SAE. Em laboratório foram realizados os estudos físicos e de observação com os óleos novos e usados. Os testes com óleo lubrificantes realizados em laboratório foram, testes físicos de viscosidade cinemática a $40^{\circ} \mathrm{C}$ e $100^{\circ} \mathrm{C}$ foi realizado em um viscosímetro saybolt, os resultados obtidos no teste realizado e apresentado em segundos "saybolt", se faz necessário efetuar uma conversão de "seg saybolt" para "centistokes" que é o grau de medição de viscosidade cinemática.

Com os resultados em viscosidade cinemática, esses dados foram utilizados para efetuar o cálculo de índice de viscosidade utilizando a formula de "Dean Davis". Os testes de observações utilizados com óleos usados, dos quais os testes de contaminação por água e filtragem dos óleos lubrificantes usados, que foram efetuados em uma chapa aquecedora, com o intuito de identificar se os lubrificantes detém contaminação por água no óleo lubrificante. Para efetuar o teste de filtragem foi utilizado filtro de vidro, "erlenmeyer" e filtro de papel, com a finalidade de analisar a coloração dos óleos lubrificantes após seu uso.

Ao decorrer do desenvolvimento do estudo ocorreram uma série de dificuldades tais como, encontrar aparelhos específicos para o desenvolvimento das análises, contudo se pôde ultrapassar os obstáculos e conseguir chegar aos resultados esperados.

As análises dos óleos lubrificantes sintéticos e semissintéticos, foram realizadas através de testes físicos e de observação em laboratório. Nessa etapa da pesquisa foi possível identificar o óleo lubrificante que tem a melhor lubrificação no motor. Os resultados foram esboçados e comparados com os dois tipos de óleos utilizados na pesquisa, e os índices estudados apresentam que o óleo lubrificante sintético é a melhor escolha para os usuários de veículos, conforme resultado do gráfico da figura 7.

Ao efetuar a comparação do grau de viscosidade SAE apresentado na embalagem dos óleos lubrificantes sintéticos e semissintéticos, com os graus de viscosidade obtidos nos testes de viscosidade cinemática com os óleos lubrificantes usados a $100^{\circ}$ $\mathrm{C}$, aponta que o grau de viscosidade SAE do óleo lubrificante semissintético aumentou, de 40 para 50, enquanto o do sintético apresentou um aumento de 40 para 60, isso aponta que o óleo lubrificante sintético com o seu uso, vai se tornando mais viscoso e assim aumentando a proteção dos componentes do motor.

Os resultados alcançados com os testes de viscosidade cinemática mostram que, a comparação de viscosidade cinemática a $40^{\circ} \mathrm{C}$ dos óleos lubrificantes sintéticos e semissintéticos novos e usados nesta pesquisa, apontam que os óleos lubrificantes sintéticos tem uma aumento na sua viscosidade cinemática de $5,15 \%$ após o uso, entretendo os lubrificantes semissintéticos tem uma aumento de $14,9 \%$ após o uso na sua viscosidade cinemática, isso demonstra que o óleos lubrificante semissintético é superior em viscosidade, isso mostra que na partida do motor quando o óleo lubrificante está frio o semissintético é melhor. Para os testes de viscosidade cinemática realizados a $100^{\circ} \mathrm{C}$, o óleo lubrificante semissintético teve um aumento em sua viscosidade cinemática de $3,47 \%$ após o uso, no entanto o óleo lubrificante sintético teve um aumento em sua viscosidade cinemática de $29,45 \%$ após o uso, isso indica que o óleo lubrificante sintético é superior ao semissintético, mostrando que o óleo lubrificante sintético oferece 
uma maior proteção aos componentes do motor em funcionamento constante.

Para efetuar a análise do índice de viscosidade se usou o cálculo de "Dean Davis" para encontrar esse índice, o gráfico da figura 8, expressa os índices de viscosidades dos óleos lubrificantes sintéticos e semissintéticos, novos e usados. O gráfico aponta que o lubrificante sintético teve um crescimento de $0,28 \%$ depois de seu uso, entretendo o óleo lubrificante semissintético após seu uso teve uma queda no seu índice de viscosidade de $-24,93 \%$, isso mostra que o óleo lubrificante sintético é superior ao semissintético mantendo respectivamente seu índice de viscosidade após seu uso, enquanto o semissintético teve uma queda brusca no seu índice de viscosidade após seu uso.

A análise de observação de contaminação por água feita como amostras de óleo lubrificantes sintéticos e semissintéticos usados, demonstrada na figura 11, indica que o óleo lubrificante semissintético tem uma maior contaminação por água do que o sintético, observou-se que o óleo lubrificante semissintético teve uma maior crepitação na chapa quente. A análise de observação feita com a filtragem do óleo lubrificante exibida na figura 11, indica no filtro de papel que o óleo lubrificante semissintético tem uma coloração mais escura do que o filtro do óleo lubrificante sintético, esses aspecto pode do óleo lubrificante semissintético, é por conta da sua composição que contem $50 \%$ de óleo mineral.

A pesquisa é importante para identificar qual o melhor lubrificante para o motor do veículo, identifica também qual óleo lubrificante oferece a melhor proteção para os componentes internos do motor. A análise foi desenvolvida para motores do ciclo otto, não se aplica em motores do ciclo diesel, por que seu óleo lubrificante tem diferentes características especificas. Os aspectos positivos são que o óleo lubrificante sintéticos apresenta maior índice após seu uso em relação ao óleo lubrificante semissintético, sua viscosidade cinemática também é maior, um único aspecto negativo dos óleos lubrificas sintéticos é que em baixa temperatura a sua viscosidade é inferior ao do óleo lubrificante semissintético.

Partindo do foco inicial para o desenvolvimento dessa pesquisa concluímos que os objetivos propostos foram alcançados. Visando a melhoria de trabalhos futuros, com óleos lubrificantes, os apontam estudos dos métodos de refino dos óleos lubrificantes utilizados, impacto ambiental dos óleos sintéticos e semissintéticos, o melhoramento da viscosidade do óleo lubrificante sintético em baixa temperatura.

\section{AGRADECIMENTOS}

Ao Centro Universitário do Norte (UNINORTE) e a Prefeitura Municipal de Manaus pelo apoio a pesquisa com bolsa de estudo.

\section{REFERÊNCIAS}

[1] GARCIA, A. G. P. Impacto da lei de eficiência energética para motores elétricos no potencial de conservação de energia na indústria. 2003. Universidade Federal do Rio de Janeiro (UFRJ).
[2] SOUSA, E. H. V. D. Análise preditiva a partir da caracterização das emissões gasosas e do óleo lubrificante em frotas com motorização a diesel. 2010.

[3] CASTRO, F. D. D. Motores automotivos: evolução, manutenção e tendências. EDIPUCRS, 2016. ISBN 8539703920.

[4] SILVEIRA, E. L. C. et al. Determinação de contaminantes em óleos lubrificantes usados e em esgotos contaminados por esses lubrificantes. Química Nova, v. 29, n. 6, p. 1193, 2006.

[5] DA SILVA, R. J. Avaliação das caracteristicas físicoquímicas usado, óleo lubrificante automotivo. 2014.

[6] BELMIRO, P. N.; CARRETEIRO, R. Lubrificantes e Lubrificação Industrial: $1^{\text {a }}$ edição, Rio de Janeiro: Editora Interciência 2006.

[7] CUNHA, R. C. Redutor de velocidade através da técnica de partículas de desgaste no óleo lubrificante auxiliada pela análise de vibrações. 2005. Universidade Estadual Paulista (UNESP).

[8] KIMURA, R. K. Uso da técnica de análise de óleo lubrificante em motores diesel estacionários, utilizando-se misturas de biodiesel e diferentes níveis de contaminação do lubrificante. 2010.

[9] BAIN \& COMPANY, Inc. Luxury Goods Worldwide Market Study Fall-Winter.2014.

[10] GOSALIA, U. Sustainability... and the Global Lubricants Industry. In: The 16th ICIS World Base Oils \& Lubricants Conference, London, 2012.

[11] CANCHUMANI, G. A. L. Óleos lubrificantes usados: um estudo de caso de avaliação de ciclo de vida do sistema de rerrefino no Brasil. 2013. Universidade Federal do Rio de Janeiro (UFRJ).

[12] PARUCKER, M. L.Desenvolvimento de materiais compósitos de baixo coeficiente de atrito com partículas de lubrificante sólido dispersas em matriz metálica a base de níquel. 2008.

[13] (GM), C. D. G. M. Óleos Lubrificares Semissintéticos. 2011.

[14] TANNÚS, D. F.; GONÇALVES, A. C. Análise do Estado de Conservação de um Redutor de Velocidade Através da Técnica de Partículas de Desgaste do Óleo Lubrificante. XI CREEM, Paper CRE04-TE03, Instituto Politécnico, Nova Friburgo RJ, 2004.

[15] TÉCNICO, B. PH análise de óleo. 2010. 